\title{
Global observations of thermospheric lunar tidal winds
}

\author{
R. S. Lieberman and D. C. Fritts \\ GESA Technical Software, Inc. (GATS), Boulder Division, Boulder, Colorado, USA \\ N. Pedatella \\ UCAR, Boulder, Colorado, USA \\ E. Doornbos \\ Aerospace Engineering, Delft University of Technology, The Netherlands \\ D. A. Ortland \\ Northwest Research Associates, Redmond, WA
}

\begin{abstract}
We present direct observations of the semidiurnal lunar tide zonal winds at $250 \mathrm{~km}$ and $350 \mathrm{~km}$ during low solar activity in 2007-2008, and 2010-2011. The migrating semidiurnal lunar tide, or $\mathrm{M}_{2}$, is a global feature with amplitudes of about $10 \mathrm{~m} \mathrm{~s}^{-1}$ at equatorial latitudes, and $20 \mathrm{~m} \mathrm{~s}^{-1}$ at high latitudes. Amplitude maximima appear twice yearly, between February and April and between August and November. $\mathrm{M}_{2}$ amplitudes during 2007-2008 are about $50 \%$ stronger than those during 2010-2011. These magnitudes are consistent with numerical predictions in WACCM-X. However, only one annual globalscale maximum is simulated during January-March.

Keywords: tide, semidiurnal, thermosphere, lunar
\end{abstract}

\section{Introduction}

Atmospheric lunar tides are global-scale oscillations driven by the gravitational force exerted by the moon (Chapman and Lindzen, 1970), and by tidallyinduced vertical motions of the ocean and solid earth (Vial and Forbes, 1994). Variations in the moon's orbit, along with the motion of the earth relative to the 
moon give rise to a spectrum of lunitidal frequencies (Siebert, 1961). The most significant of these is the $\mathrm{M}_{2}$ lunar semidiurnal tide, with a zonal wavenumber of 2 , and a period of 12.42 solar hours, or one half of a lunar day. Dynamically speaking, lunar tides are global scale, vertically propagating inertia-gravity waves whose ampitudes increase with altitude up to about $10 \mathrm{~m} \mathrm{~s}^{-1}$ at meteor heights. The predicted vertical wavelength of the classical main $\mathrm{M}_{2}$ mode is about $100 \mathrm{~km}$ (Chapman and Lindzen, 1970).

Interest in the lunar tides has intensified in recent years owing to their apparent role in linking sudden stratospheric warming events (SSW) to ionospheric variability. Several studies have associated SSW with enhanced lunar variability in the equatorial electrojet and vertical plasma drifts (Fejer et al., 2010, 2011), and in the geomagnetic field (Yamazaki et al., 2012). Pedatella et al. (2012) reported global lunar tide amplification of 50-60\% in the NCAR Whole Atmosphere Community Climate Model (WACCM) during SSW simulations. Forbes and Zhang (2012) observed lunar tidal enhancements in the mesosphere and thermosphere during January 2009, when significant SSW occurred. Using the Global Scale Wave Model (GSWM), they showed that with zonal mean winds and temperatures attending SSW, a normal mode appears at 12.43 hours that would ehnance the $\mathrm{M}_{2}$ 12.42-hour response.

Because of the close proximity between lunar and solar tidal frequencies, and the weaker amplitudes of the lunar tides, isolating $\mathrm{M}_{2}$ in data presents a challenge. Very long records of ground-based observations are required in order to effectively resolve lunar and solar tides. $\mathrm{M}_{2}$ winds have been inferred from mesospheric radar measurements spanning intervals ranging from 10-20 years (Stening et al., 1987; Stening and Vincent, 1989; Stening and Jacobi, 2001; Sandford et al., 2006; Niu et al., 2007). $\mathrm{M}_{2}$ wind amplitudes maximize near $10 \mathrm{~m} \mathrm{~s}^{-1}$ in the lower thermosphere. Observed vertical wavelengths ranged between 17 and $80 \mathrm{~km}$.

The separation between solar and lunar tidal periods becomes more pronounced when these phenomena are observed from a satellite frame of reference (Forbes et al., 2013). A wave with zonal wavenumber $m$ and frequency $\sigma$ (in 
radians per day) with respect to the Earth is viewed from a low Earth orbiting satellite as an oscillation with an aliased frequency

$$
k_{s}=\frac{\left|c_{0}\right| m-\sigma}{\sqrt{1+c_{0}^{2}}}
$$

(Salby, 1982). $c_{0}$ is the rate at which observations drift around a latitude circle, and is $-2 \pi$ radians day $^{-1}$ for satellites in a sun-synchronous orbit. When viewed from this platform, the migrating solar semidiurnal tide with $\mathrm{m}=2$ and a period of 12 hours ( .5 days) registers as an invariant feature $\left(k_{s}=0\right)$, while the lunar semidiurnal tide (with $\mathrm{m}=2$ and a period of 12.42 hours) will have an apparent period of roughly 15 days $\left(k_{s}=0.067\right)$. Thus, polar- and low-orbiting satellite data are particularly well-suited to the study of global lunar tides. Forbes et al. (2013) exploited these properties to document lunar tides in mesospheric and lower thermospheric temperatures, and in thermospheric densities during the solar minimum period of 2007-2010. Zhang and Forbes (2013) examined $\mathrm{M}_{2}$ winds between $80-100 \mathrm{~km}$ from the UARS High Resolution Doppler imager (HRDI).

Thermospheric winds play an important role in ionosphere-thermosphere coupling, through dynamo generation and transport of plasma along magnetic field lines. Motivated by the apparent significance of the lunar tide for stratosphereionosphere coupling, the purpose of this paper is to document the contribution of $\mathrm{M}_{2}$ to thermospheric zonal winds. We analyze winds from the CHAllenging Minisatellite Payload (CHAMP) and Gravity Field and Steady-State Ocean Circulation Explorer (GOCE) missions during the years surrounding the 2009 solar minimum. Monthly mean $\mathrm{M}_{2}$ behavior is presented in CHAMP and GOCE zonal winds, and compared with simulations of $\mathrm{M}_{2}$ in the extended WACCM model, or WACCM-X. Our findings indicate that $\mathrm{M}_{2}$ is a climatological feature of the thermospheric wind near solar minimum, that exhibits interannual variability and possible sensitivity to the background wind. 


\section{Data and Analysis}

\section{1. $C H A M P$}

CHAMP was a 10-year mission managed by the GeoForschungsZentrum (GFZ) in Germany. The primary mission goals were mapping of Earth's magnetic and gravity fields, and the collection of refraction data for characterizing the troposphere and the ionosphere. Although CHAMP was not designed for studies of the thermosphere, it carried a Spatial Triaxial Accelerometer for Research (STAR) that measured nongravitational forces acting on the spacecraft, among which the drag is dominant (Bruinsma et al., 2004). Cross-track winds have been derived from acceleration values by Liu et al. (2006) and Doornbos et al. (2010). This study uses the wind dataset derived by Doornbos et al. (2010), distributed at http://thermosphere.tudelft.nl/acceldrag/data.php?cat=CH_PN_R02.

CHAMP was stabilized in a circular, near-polar orbit starting at about 450 $\mathrm{km}$ in 2000 and descending to $265 \mathrm{~km}$ by September 2010. Between roughly $65^{\circ} \mathrm{S}$ and $65^{\circ} \mathrm{N}, \mathrm{CHAMP}$ ground-relative orbit tracks are aligned north-south, implying that the crosswind orientation is east-west, or zonal. Daily measurements are fixed in local solar time, with a separation of approximately 12 hours between the ascending and descending node observations. The orbital precession of CHAMP $\left(c_{0} \sim-6.3\right.$ radians day $\left.{ }^{-1}\right)$ results in 12 hours of lunar local time coverage within 13.3 days.

CHAMP winds have been computed for 2003-2008. This study utilizes winds in 2007 and 2008, the available years closest to the 2009 solar minimum (see Figure 1). Our analysis begins with the formation of daily longitudinal averages of the east-west crosswind, binned in latitude and segregated by ascending and descending parts of the orbit. We follow the strategy described by Forbes et al. (2013), which is based on the property that according to (1), $\mathrm{M}_{2}$ is viewed by CHAMP as an oscillation of the zonal mean zonal wind $(\bar{U})$ with a period of roughly 13.3 days. It is important to bear in mind that the $\mathrm{M}_{2}$ tide is considerably weaker than the time-mean and the solar migrating tidal winds, which are also represented in the daily longitudinal averages (Lieberman et al., 
2013). We therefore filter these components by subtracting 14-day averages of the zonal mean zonal wind from each daily value. The "residual" zonal mean zonal winds, denoted $\bar{U}_{\text {res }}$, are binned in lunar local time, and composited over 54-day blocks in order to average over 18-24 hours of local solar time. At each latitude, a 12-hour harmonic $\left(\mathrm{M}_{2}\right)$ is fit to the lunar local time composites.

\section{2. $G O C E$}

The Gravity Field and Steady-State Ocean Circulation Explorer (GOCE) was a European Space Agency (ESA) satellite intended to map the Earth's gravity field in unprecedented detail. The mission commenced on March 17, 2009 and ended November 11, 2013 when the spacecraft re-entered Earth's atmosphere. We examined $\mathrm{M}_{2}$ GOCE winds between November 2009-July 2011, when solar flux conditions were fairly similar to the CHAMP data analysis period. (See Figure 1.) Data are distributed at https://earth.esa.int/web/guest/missions/esaoperational-missions/goce/goce-thermospheric-data

The primary onboard instrumentation was a highly sensitive gravity gradiometer consisting of three pairs of accelerometers which measured gravitational gradients along three orthogonal axes. To gain the best possible measurements, the satellite was stabilized in an extremely low orbit $(255 \mathrm{~km}$ above Earth), where it was subjected to air drag. This drag was compensated by an electric ion engine that generated carefully calculated thrust. Accelerometer and thrust activation data were used to detect the aerodynamic force on the satellite. Cross-winds and density were determined by iterating wind and density inputs to an aerodynamic model of the satellite, until the modeled aerodynamic accelerations matched the observations (Doornbos et al., 2013).

GOCE was launched in a nearly sun-synchronous orbit, with equatorial local time crossings of 18.0 (6.0) LST on the ascending (descending) portions of the orbit. (Over the lifetime of the mission, these crossing times increased by one hour and 36 minutes.) However, the lunar local time precessed by approximately 52 minutes per day, tracing out a full 12-hour cycle over a 15-day period. The analysis of GOCE data was therefore very similar to the CHAMP data. Daily 
longitudinal averages of the east-west crosswind are formed, binned in latitude and segregated by ascending and descending parts of the orbit. A 15-day average of the zonal mean zonal wind is then subtracted from each daily value, to form residuals filtered of time-mean and migrating solar tidal components. Residual winds are then binned in lunar local time. To facilitate comparison with CHAMP $\mathrm{M}_{2}$ winds, we composite GOCE winds in lunar local time bins over 54-day blocks. This averaging was undertaken for CHAMP in order to span 24 hours of local solar time; however, GOCE local times do not change significantly over this interval. At each latitude, a 12-hour harmonic is then fit to the GOCE lunar local time wind composites.

\subsection{Numerical models}

The observations of $\mathrm{M}_{2}$ in thermospheric zonal wind are compared with simulations of $\mathrm{M}_{2}$ in WACCM-X. WACCM-X extends from the surface to the upper thermosphere $\left(2.5 \times 10^{-9} \mathrm{hPa}\right)$, and includes the dynamical, chemical, and physical processes that are necessary to simulate the troposphere, stratosphere, mesosphere, and thermosphere. A detailed description of WACCM-X is provided by Liu et al. (2010), and is not repeated herein. The model horizontal resolution is $1.9^{\circ}$ in latitude and $2.5^{\circ}$ in longitude. The vertical resolution ranges from $\sim 1.5 \mathrm{~km}$ in the troposphere to a half scale height in the upper thermosphere. The simulations are performed under constant solar minimum $(\mathrm{F} 10.7=70)$, and quiet geomagnetic conditions. The $\mathrm{M}_{2}$ lunar tide forcing is added to WACCM-X using the approach outlined by Pedatella et al. (2012).

For the present study, we have performed a one-year WACCM-X simulation. The simulation is free-running, and thus not representative of any particular time period. We note that since we only consider a one-year WACCM-X simulation, the comparison between the simulated $\mathrm{M}_{2}$ and that observed by CHAMP and GOCE may be impacted by interannual variability.

To understand how recurrent geomagnetic activity may alias into the observations of M2, we have performed additional simulations using the National Center for Atmospheric Research Thermosphere-Ionosphere-Electrodynamics Gen- 
eral Circulation Model (TIE-GCM). TIE-GCM is a first principles model of the ionosphere and thermosphere, including self-consistent electrodynamics (Richmond et al., 1992). The TIE-GCM altitude domain is from $\sim 97 \mathrm{~km}$ to $400-700$ $\mathrm{km}$, with the upper boundary altitude depending on solar activity conditions due to the use of a pressure coordinate system. The TIE-GCM simulations are performed with a horizontal resolution of $5^{\circ}$ in latitude and longitude, and a vertical resolution of two points per scale height. The impact of geomagnetic activity on thermosphere zonal winds is simulated for 2007-2008 by imposing the Weimer (2005) electric potential model at high latitudes in the TIE-GCM. Realistic variability of the F10.7 cm solar flux is also included in the TIE-GCM simulations. Migrating diurnal and semidiurnal tides are specified at the model lower boundary using the climatological Global Scale Wave Model (Hagan and Forbes, 2002, 2003). Lunar tides are not included in the TIE-GCM simulations, and any variability at lunar periods can therefore be attributed to aliasing that results from periodic geomagnetic variability.

\section{Global structure of $\mathrm{M}_{2}$}

We begin by examining the evolution of $\bar{U}_{r e s}$ in lunar local time. This behavior is shown in Figure 2, derived from CHAMP measurements during April 2007 and 2008. The $\mathrm{M}_{2}$ fits are juxtaposed upon $\bar{U}_{\text {res }}$ as dotted curves. The error bars shown indicate the sensitivity of $\bar{U}_{\text {res }}$ to the CHAMP measurement uncertainty, and average about $6.3 \mathrm{~m} \mathrm{~s}^{-1}$. This quantity was computed by iterating the analysis method 300 times upon a prescribed combination of time-mean, solar tidal, and $\mathrm{M}_{2}$ lunar tidal wind fields, perturbed by random fluctuations scaled by CHAMP's measurement uncertainty of $140 \mathrm{~m} \mathrm{~s}^{-1}$. The error bars connect the values of $\bar{U}_{\text {res }} \pm$ one standard deviation. The $\mathrm{M}_{2}$ oscillation is clearly evident in many of the extratropical time traces, and is the dominant feature at $40^{\circ} \mathrm{S}, 20^{\circ} \mathrm{S}$ and $80^{\circ} \mathrm{N}$. The uncertainty of the $\mathrm{M}_{2}$ amplitude to the analysis method (not plotted) is about $4 \mathrm{~m} \mathrm{~s}^{-1}$.

Monthly amplitudes and phases of CHAMP $\mathrm{M}_{2}$ are plotted in Figure 3. 
These determinations were made with winds from 2007-2008. Amplitudes are global in extent, and maximize during equinoxes. During the autumnal equinox a maximum of $15 \mathrm{~m} \mathrm{~s}^{-1}$ is centered about the equator, while the maximum of $12 \mathrm{~m} \mathrm{~s}^{-1}$ at vernal equinox is shifted toward the southern hemisphere. During these periods of maxima, the phase of $\mathrm{M}_{2}$ is fairly uniform in latitude, with values between 7-8 hours. Additional maxima appear at the highest latitudes: $20 \mathrm{~m} \mathrm{~s}^{-1}$ in April in the southern hemisphere, and $15 \mathrm{~m} \mathrm{~s}^{-1}$ in the northern hemisphere. The maxima in the high southern latitudes are attended by a phase between 9-10 hours. These high-latitude phenomena will be discussed in connection to Figure 6.

Figure 4 shows monthly amplitudes and phases of $\mathrm{M}_{2}$ derived from GOCE winds between November 2009-August 2011. While the method of analysis is identical to that used for CHAMP, we reiterate that GOCE measurements are virtually sun-synchronous, and therefore (unlike CHAMP) only two local times are represented in the processing of GOCE winds. As in the case of CHAMP $\mathrm{M}_{2}$, amplitudes have a global extent with twice-yearly maxima. Amplitudes are somewhat weaker than CHAMP $\mathrm{M}_{2}$, maximizing at $11 \mathrm{~m} \mathrm{~s}^{-1}$. The first maximum of the year is centered on the equator, and occurs between January and March, compared to April as seen in CHAMP, while the fall GOCE maximum is shifted to October. An additional localized maximum is seen in July at the northern polar latitudes. Phase values range between 6-7 hours When $\mathrm{M}_{2}$ amplitudes are strong, which is about 1 hour earlier than seen in CHAMP $\mathrm{M}_{2}$.

Figure 5 is the WACCM-X counterpart to Figure 3. The figure is obtained by evaluating the time-mean wind, migrating solar diurnal and semidiurnal tides, and $\mathrm{M}_{2}$ in WACCM at $350 \mathrm{~km}$ at at CHAMP coordinates, and then processing the pseudo-data identically to the CHAMP values, as described in section 2.1 Some similarities can be discerned among $\mathrm{M}_{2}$ in WACCM-X and CHAMP $\mathrm{M}_{2}$. WACCM-X $M_{2}$ exhibits global structure, with maximum values of $10 \mathrm{~m}^{-1}$ that extend from January-March. The hour of maximum lies between 8 and 9 hours, about one hour later than in CHAMP. However, a number of differences between $\mathrm{M}_{2}$ in CHAMP and WACCM-X are observed, including 1. The primary 
WACCM-X maxima, centered in February, are located near $50^{\circ} \mathrm{N}$ and $50^{\circ} \mathrm{S}$, as opposed to the equator as seen in CHAMP. 2. WACCM-X M $\mathrm{M}_{2}$ exhibits a localized autumnal equinox maximum in the high-latitude northern hemisphere, whereas in CHAMP the maxima are centered on the equator, and in the highlatitude southern hemisphere. 3. The global maximum in WACCM-X spanning January-February-March is actually initiated in the southern hemisphere in December.

WACCM-X M $\mathrm{M}_{2}$ winds at $260 \mathrm{~km}$ (not shown) are virtually identical to those at $350 \mathrm{~km}$. We therefore also compare $\mathrm{M}_{2}$ in GOCE (Figure 2) with Figure 4. The two fields are similar insofar as both show global-scale structure between January and March. However, GOCE shows a stronger maximum over the equator, and its phase preceeds WACCM-X phases by about 2 hours. A maximum oberved in GOCE winds in July in the northern hemisphere does not appear in WACCM-X. GOCE also exhibits a global-scale maximum in October, in contrast to the localized maximum in WACCM-X that is centered on $50^{\circ} \mathrm{N}$.

\section{Discussion}

The thermospheric $\mathrm{M}_{2}$ tide in the zonal wind has been examined in CHAMP and GOCE data during conditions of relatively low solar activity. The global structure and magnitude of latitude versus month composites of $\mathrm{M}_{2}$ are qualitatively similar in the two datasets. The most prominent features are low latitude $\mathrm{M}_{2}$ amplitude maxima between $10-15 \mathrm{~m} \mathrm{~s}^{-1}$ that occur twice yearly. Differences occur between the two datasets in the latitudes and timing of these maxima, and the hour of maximum in GOCE occurs about an hour earlier than in CHAMP data. In comparison, $\mathrm{M}_{2}$ in WACCM-X exhibits only one global-scale maximum per year, ocurring between January-March.

To explore the differences among the data and the model, we consider the possible influence of a 13.5-day oscillation in the $\mathrm{K}_{p}$ geomagnetic index upon $\bar{U}_{r e s}$, and $\mathrm{M}_{2}$. High-speed solar wind streams from low-latitude coronal holes induce solar and geomagnetic activity at the solar rotational period (27 days) 
and its subharmonics, including 13.5 days (Ram et al., 2012; Zhang et al., 2014). The 13.5-day period is close to the 13.3-day period at which $\mathrm{M}_{2}$ is viewed by CHAMP, and the 14.7-day period that GOCE sampling associates with $\mathrm{M}_{2}$. Because thermospheric winds and density are sensitive to short-term geomagnetic variations (Zhang et al., 2014), we therefore attempted to quantify the leakage of a 13.5-day variation in $\bar{U}_{\text {res }}$ into $\mathrm{M}_{2}$.

To compute the effects of periodic geomagnetic activity on thermospheric winds, the NCAR TIE-GCM was run for 2 2-year periods (2007-2008 and 20102011) with realistic geomagnetic forcing, but without lunartidal forcing. Hourly model output fields were then sampled over the 2007-2008 (2010-2011) period at CHAMP (GOCE) coordinates and processed for $\mathrm{M}_{2}$ as described in sections 2.1 and 2.1. Figure 6 presents non-lunar variability at the $\mathrm{M}_{2}$ period in TIE-GCM (presumably due to geomagnetic sources) sampled by CHAMP. These effects are negligible at equatorial latitudes and most significant at high latitudes. Comparing Figures 3 and 6 we speculate that the $\mathrm{K}_{p}$ effect upon $\bar{U}_{\text {res }}$ may account for the high CHAMP $\mathrm{M}_{2}$ values observed at northern hemisphere polar latitudes during February-May, and poleward of $50^{\circ} \mathrm{S}$ between January and April. The transition to higher values of $\mathrm{M}_{2}$ near $40^{\circ} \mathrm{S}$ during vernal equinox may account for some of the asymmetry about the equator of the CHAMP equinox (March-April) maximum.

Figure 7 is the GOCE counterpart to Figure 6. As in the case of CHAMP, the effects of geomagnetic forcing upon $\mathrm{M}_{2}$ are negligible between $40^{\circ} \mathrm{S}-40^{\circ} \mathrm{N}$, and quite significant at polar latitudes, particularly in the northern hemisphere. Comparing Figures 7 and 4 suggests that aliasing of the geomagnetic-related $\bar{U}_{\text {res }}$ activity could account in part for the high-latitude extensions of GOCE $\mathrm{M}_{2}$ during October.

The $\mathrm{M}_{2}$ features observed in Figures 3, 4 and 5 have been influenced in part by the background conditions between the surface and the altitudes of GOCE $(\sim 250)$ and CHAMP $(\sim 350 \mathrm{~km})$. The monthly evolution of WACCM-X $\bar{U}$, at $70 \mathrm{~km}$ is quite consistent overall with balanced $\bar{U}$ computed from TIMED SABER geopotential (Figure 8, left). At $100 \mathrm{~km}$, WACCM-X and TIMED TIDI 
$\bar{U}$ show qualitative agreement. An annual cycle appears in both datasets, with westward (eastward) $\bar{U}$ in the winter (summer) hemisphere. However, TIDI $\bar{U}$ shows this behavior only poleward of $20^{\circ}$, with time-mean westward $\bar{U}$ between $20^{\circ} \mathrm{S}-20^{\circ} \mathrm{N}$.

Figure 9 compares CHAMP and WACCM-X $\bar{U}$. (Time mean winds for GOCE cannot be determined due to undersampling in local time.) At low latitudes, CHAMP $\bar{U}$ is quite weak and little seasonal variation can be discerned. The most prominent feature is an annual variation away from the tropics, characterized by westward winds in the summer hemisphere and eastward winds in the winter hemisphere. Eastward winds peak at $30 \mathrm{~m} \mathrm{~s}^{-1}$, while westward winds are stronger, maximizing at $-70 \mathrm{~m} \mathrm{~s}^{-1}$. WACCM-X $\bar{U}$ differs in many ways from CHAMP. The annual cycle is very weak, and winds are predominantly eastward, except at very high latitudes where weak westward winds are found. The strongest $\mathrm{M}_{2}$ amplitudes are observed during periods of light winds $(|\bar{U}| \leq 10)$ at $350 \mathrm{~km}$. In the case of CHAMP $\mathrm{M}_{2}$, this juxtaposition is seen between $40^{\circ} \mathrm{S}-30^{\circ} \mathrm{N}$ during vernal and autumnal equinox. In WACCM-X, light winds coincide with high $\mathrm{M}_{2}$ at non-equatorial latitudes during January-March, in the high-latitude southern hemisphere in December, and poleward of $40^{\circ} \mathrm{N}$.

\section{Summary}

This investigation was motivated by empirical studies that identify lunar tides as agents of stratosphere-ionosphere-thermosphere coupling. The monthly $\mathrm{M}_{2}$ lunar tide in thermospheric zonal winds has been examined in CHAMP and GOCE data, and in WACCM-X during conditions of relatively low solar activity. The $\mathrm{M}_{2}$ oscillation as seen in CHAMP and GOCE winds is global-scale, characterized by two separate centers of action. One of these consists of strongamplitude features at very high latitudes, that may in part reflect spurious, nontidal $\bar{U}_{\text {res }}$ oscillations due to geomagnetic activity at a 13.5 day subharmonic of the solar rotation. We also identify robust, low- and mid-latitude cells of $\mathrm{M}_{2}$ with peak amplitudes ranging between 10-15 $\mathrm{m} \mathrm{s}^{-1}$. At $350 \mathrm{~km}$ (CHAMP), 
these features maximize at equinox, while at $250 \mathrm{~km}$ (GOCE), the equinox maxima are shifted one month closer to the winter season (e. g., from March to February, and from September to October). These differences might be due to GOCE and CHAMP observing different years. Moreover, unlike CHAMP, GOCE $\mathrm{M}_{2}$ calculations are not averaged over all local solar times.

$\mathrm{M}_{2}$ observations were compared to predictions in WACCM-X. Amplitudes are comparable with CHAMP and GOCE, but the model exhibits only one global-scale maximum per year, ocurring between January-March. While differences between CHAMP, GOCE and WACCM-X $\mathrm{M}_{2}$ cannot be fully explained at the present time, one possible source may lie in the differences in the thermospheric zonal mean zonal wind structure. We conclude that $\mathrm{M}_{2}$ is a climatological feature of the thermospheric wind system, with the potential to modulate transport of plasma along magnetic field lines.

\section{Acknowledgments}

RSL wishes to thank Drs. J. M. Forbes and X. Zhang for helpful suggestions. This research was supported by NASA grants NNH12CF02C and NNH12CF66C, and by NSF grant AGS-1243364. 


\section{References}

Bruinsma, S., Tamagnan, D., Biancale, R., 2004. Atmospheric densities derived from CHAMP/STAR accelerometer observations. Planet. Space Sci. 52 (4), $297-312$.

Chapman, S., Lindzen, R. S., 1970. Atmospheric Tides. Gordon and Breach, New York.

Doornbos, E., Bruinsma, S., Fritsche, B., Koppenwallner, G., Visser, P., van den Ijssel, J., de Teixeira de Encarnação, J., 2013. Goce + theme 3: Air density and wind retrieval using GOCE data. Tech. Rep. 4000102847/NL/EL, eSA Contract Report.

Doornbos, E., van den Ijssel, J., Lühr, H., Förster, M., Koppenwallner, G., 2010. Neutral density and crosswind determination from arbitrarily oriented multiaxis accelerometers on satellites. J. Spacecraft and Rockets 47 (4), 580-589.

Fejer, B. G., Olson, M. E., Chau, J. L., Stolle, C., Lühr, H., Goncharenko, L. P., Yumoto, K., Nagatsuma, T., 2010. Lunardependent equatorial ionospheric electrodynamic effects during sudden stratospheric warmings. J. Geophys. Res. 115, A00G03, doi:10.1029/2010JA015273.

Fejer, B. G., Tracy, B. D., Olson, M. E., Chau, J. L., 2011. Enhanced lunar semidiurnal equatorial vertical plasma drifts during sudden stratospheric warmings. Geophys. Res. Letts. 38 (L21104), doi:10.1029/2011GL049788.

Forbes, J. M., Zhang, X., 2012. Lunar tide amplification during the January 2009 stratosphere warming event: Observations and theory. J. Geophys. Res. 117 (A12312), doi:10.1029/2012JA017963.

Forbes, J. M., Zhang, X., Bruinsma, S., Oberheide, J., 2013. Lunar semidiurnal tide in the thermosphere under solar minimum conditions. J. Geophys. Res. 118, 17881801, doi:10.1029/2012JA017962. 
Hagan, M. E., Forbes, J. M., 2002. Migrating and nonmigrating diurnal tides in the middle and upper atmosphere excited by tropospheric latent heat release. J. Geophys. Res. 107 (D24), doi:10.1029/2001JD001236.

Hagan, M. E., Forbes, J. M., 2003. Migrating and nonmigrating semidiurnal tides in the middle and upper atmosphere excited by tropospheric latent heat release. J. Geophys. Res. 108 (A2), doi:10.1029/2002JA009466.

Lieberman, R. S., Akmaev, R. A., Fuller-Rowell, T. J., Doornbos, E., 2013. Thermospheric zonal mean winds and tides revealed by CHAMP. Geophys. Res. Letts. 40, doi:10.1002/grl.50481.

Liu, H., Lühr, H., Watanabe, S., Köhler, W., Henize, V., Visser, P., 2006. Zonal winds in the equatorial upper thermosphere: Decomposing the solar flux, geomagnetic activity, and seasonal dependencies. J. Geophys. Res. 111 (A07307), doi:10.1029/2005JA011415.

Liu, H.-L., Foster, B. T., Hagan, M. E., McInerney, J. M., Maute, A., Qian, L., Richmond, A. D., Roble1, R. G., Solomon, S. C., Garcia, R. R., Kinnison, D., Marsh, D. R., Smith, A. K., Richter, J., Sassi, F., Oberheide, J., 2010. Thermosphere extension of the Whole Atmosphere Community Climate Model. J. Geophys. Res. 115 (A12302), doi:10.1029/2010JA015586.

Niu, X. J., Xiong, J. G., Wan, W. X., Ning, B. Q., Liu, L. B., 2007. A measurement of the lunar semidiurnal tide at Wuhan $\left(30^{\circ} 40^{\prime} \mathrm{n}, 114^{\circ} 30^{\prime} \mathrm{e}\right)$. Earth, Planets and Space 59, 991997.

Pedatella, N. M., Liu, H. L., Richmond, A. D., Maute, A., Fang, T. W., 2012. Simulations of solar and lunar tidal variability in the mesosphere and lower thermosphere during sudden stratosphere warmings and their influence on the low-latitude ionosphere. J. Geophys. Res. 117 (A08326), doi:10.1029/2012JA017858.

Ram, S. T., Yamamoto, M., Veenadhari, B., Kumar, S., Gurubaran, S., 2012. Corotating interaction regions (CIRs) at sub-harmonic solar rotational peri- 
ods and their impact on ionosphere-thermosphere system during the extreme low solar activity year 2008. Indian J. Radio Space Sci. 41 (2), 294-305.

Richmond, A. D., Ridley, E. C., Roble, R. G., 1992. A thermosphere/ionosphere general circulation model with coupled electrodynamics. Geophys. Res. Letts. 19, doi:10.1029/92GL00401.

Salby, M. L., 1982. Sampling theory for asynoptic satellite observations. Part I: Space-time spectra, resolution, and aliasing. J. Atmos. Sci. 39, 2577-2601.

Sandford, D. J., Muller, H. G., Mitchell, N. J., 2006. Observations of lunar tides in the mesosphere and lower thermosphere at Arctic and middle latitudes. Atmos. Chem. Phys. 6, 4117-4127.

Siebert, M., 1961. Atmospheric tides. Adv. Geophys. 7, 105-187.

Stening, R. J., Jacobi, C., 2001. Lunar tidal winds in the upper atmosphere over Collm. Ann. Geophysicae 18, 1645-1650.

Stening, R. J., Meek, C. E., Manson, A. H., 1987. Lunar tidal winds measured in the upper atmosphere $(78-105 \mathrm{~km})$ at Saskatoon, Canada. J. Atmos. Sci. $44,11431151$.

Stening, R. J., Vincent, R. A., 1989. A measurement of lunar tides in the mesosphere at Adelaide, South-Australia. J. Geophys. Res. 94, 10,121-10,129.

Vial, F., Forbes, J. M., 1994. Monthly simulations of the lunar semi-diurnal tide. J. Atmos. Terr. Phys. 56 (12), 1691-1607.

Weimer, D. R., 2005. Improved ionospheric electrodynamic models and application to calculating Joule heating rates. J. Geophys. Res. 110 (A05306), doi:10.1029/2004JA010884.

Yamazaki, Y., Richmond, A. D., Yumoto, K., 2012. Stratospheric warmings and the geomagnetic lunar tide: 19582007,. J. Geophys. Res. 117 (A04301), doi:10.1029/2012JA017514. 
Zhang, J. T., Forbes, J. M., 2013. Lunar tidal winds between 80 and 110 $\mathrm{km}$ from UARS/HRDI wind measurements. J. Geophys. Res. 118, 52965304, doi:10.1002/jgra.50420.

Zhang, J. T., Forbes, J. M., Zhang, C. H., Doornbos, E., Bruinsma, S. L., 2014. Lunar tide contribution to thermosphere weather. Space Weather 12, doi:10.1002/2014SW001079. 


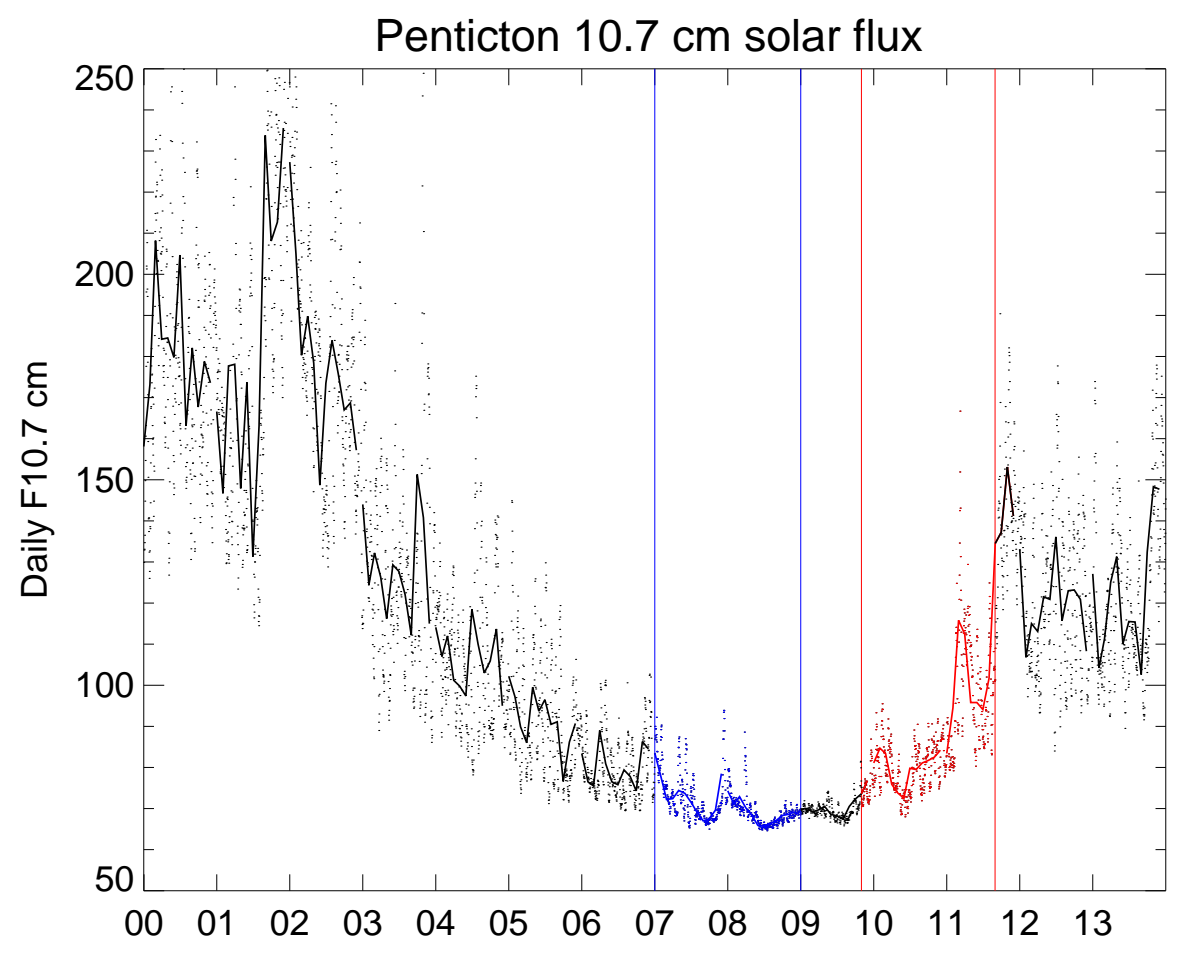

Figure 1: $10.7 \mathrm{~cm}$ solar radio flux ( $\mathrm{F}_{10.7}$ spanning 2000-2013. Dots are daily values, solid lines are monthly mean values. Thin vertical lines bracket the intervals of CHAMP (blue) and GOCE (red) sampling. 
(a) Apr U (m/s) Lat $=-60$

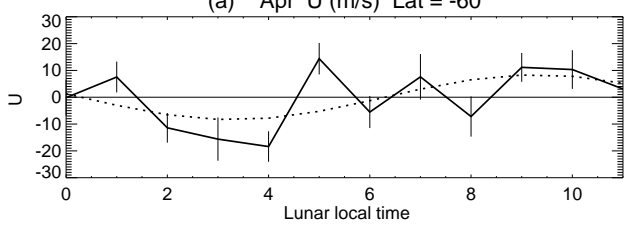

(b) $\operatorname{Apr} \cup(\mathrm{m} / \mathrm{s})$ Lat $=-40$

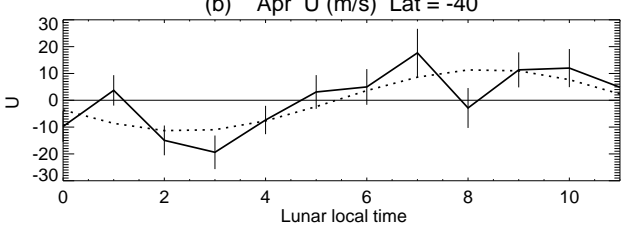

(c) Apr $\cup(\mathrm{m} / \mathrm{s})$ Lat $=-20$

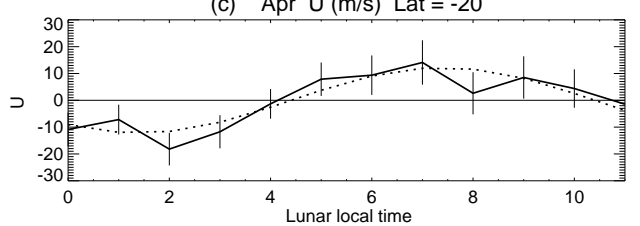

(d) $\operatorname{Apr} \cup(\mathrm{m} / \mathrm{s})$ Lat $=0$

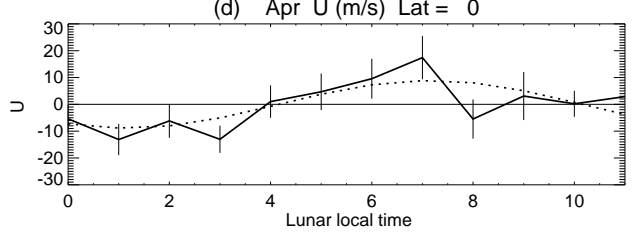

(e) $\operatorname{Apr} \cup(\mathrm{m} / \mathrm{s})$ Lat $=20$

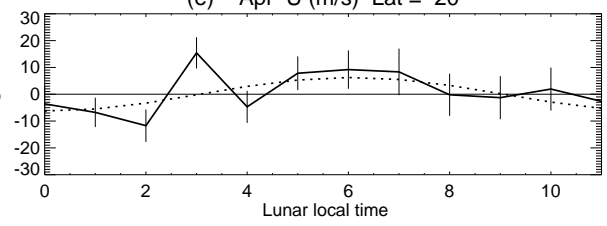

(f) $\operatorname{Apr} \cup(\mathrm{m} / \mathrm{s})$ Lat $=40$

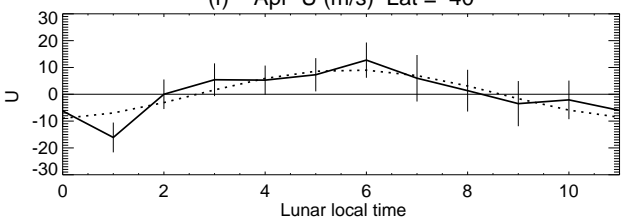

(g) Apr $\cup(\mathrm{m} / \mathrm{s})$ Lat $=60$

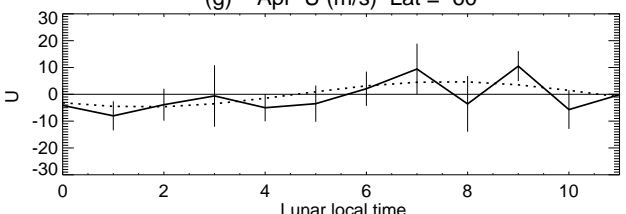

(h) $\operatorname{Apr} \cup(\mathrm{m} / \mathrm{s})$ Lat $=80$

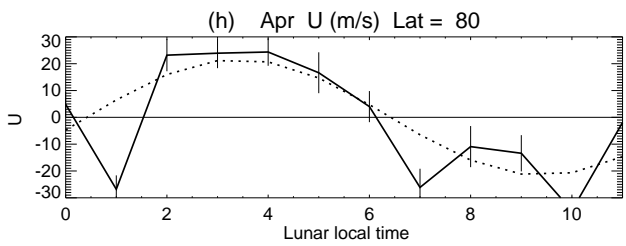

Figure 2: Solid curves are CHAMP $\bar{U}_{\text {res }}$ plotted as a function of lunar local time in April at (a) $60^{\circ} \mathrm{S}$, (b) $40^{\circ} \mathrm{S}$, (c) $20^{\circ} \mathrm{S}$, (d) equator, (e) $20^{\circ} \mathrm{N}$, (f) $40^{\circ} \mathrm{N}$, (g) $60^{\circ} \mathrm{N}$ and (h) $80^{\circ} \mathrm{N}$. Dotted curves are $\mathrm{M}_{2}$ fits. This vertical lines are the $\bar{U}_{r e s}$ values \pm one standard deviation. 

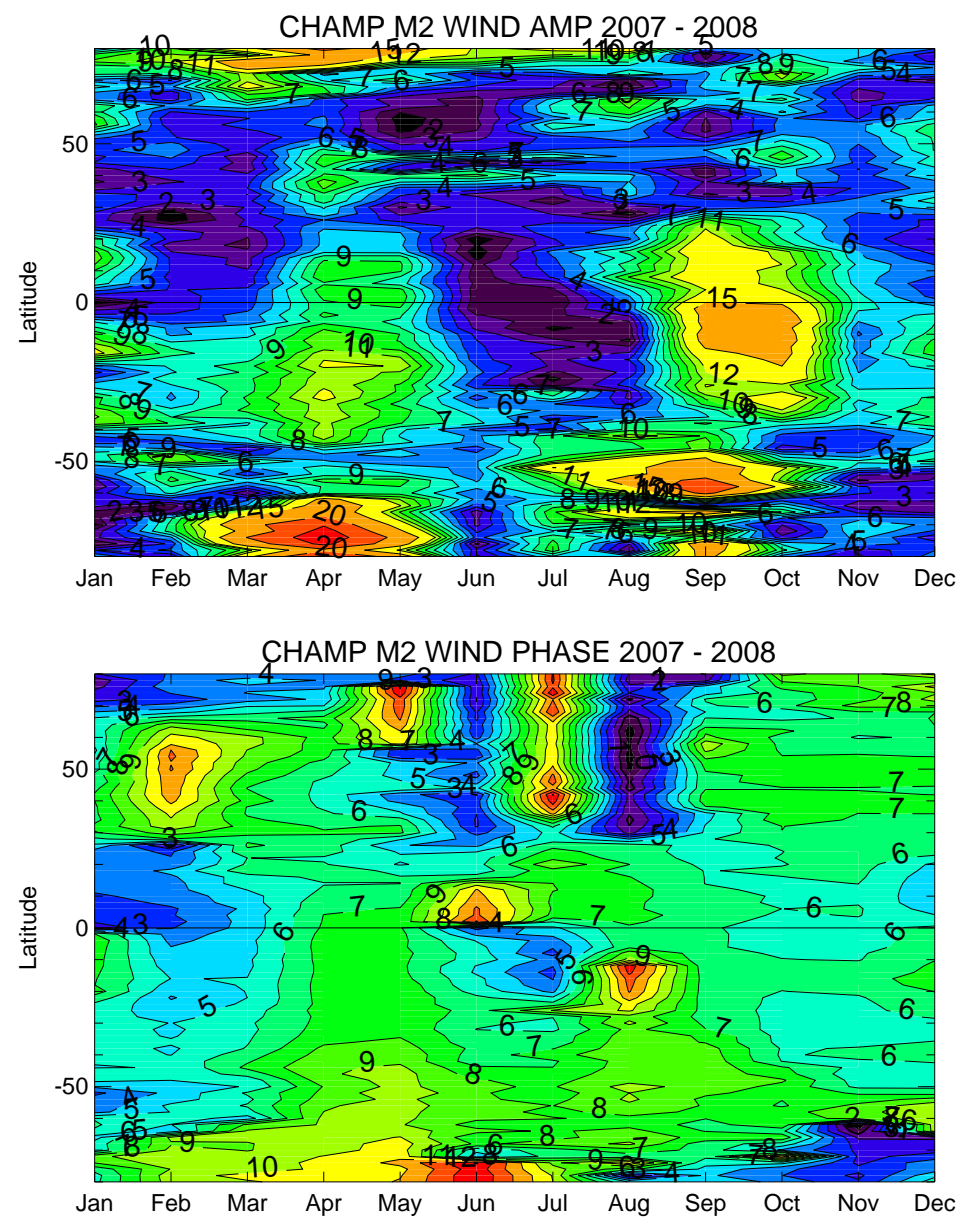

Figure 3: $\mathrm{M}_{2}$ amplitude (top) and phase (bottom) as a function of latitude and month. Values are derived from CHAMP $\bar{U}_{\text {res }}$ values spanning 2006-2008. Contour interval is $1 \mathrm{~m} \mathrm{~s}^{-1}$ (top) and 1 hour (bottom). 

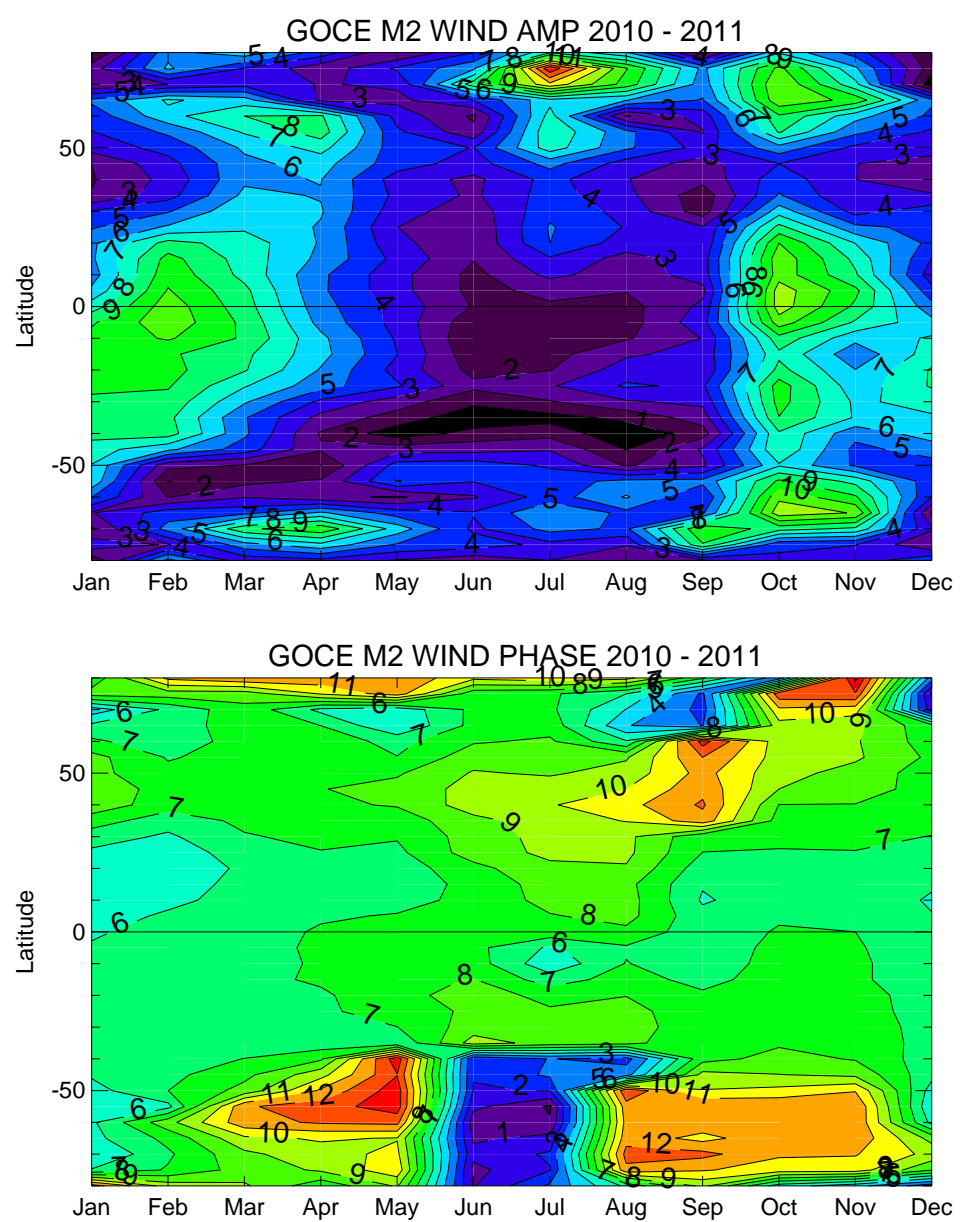

Figure 4: $\mathrm{M}_{2}$ amplitude (top) and phase (bottom) as a function of latitude and month. Values are derived from GOCE $\bar{U}_{\text {res }}$ values spanning November 2009-August 2011. Contour interval is $1 \mathrm{~m} \mathrm{~s}^{-1}$ (top) and 1 hour (bottom). 

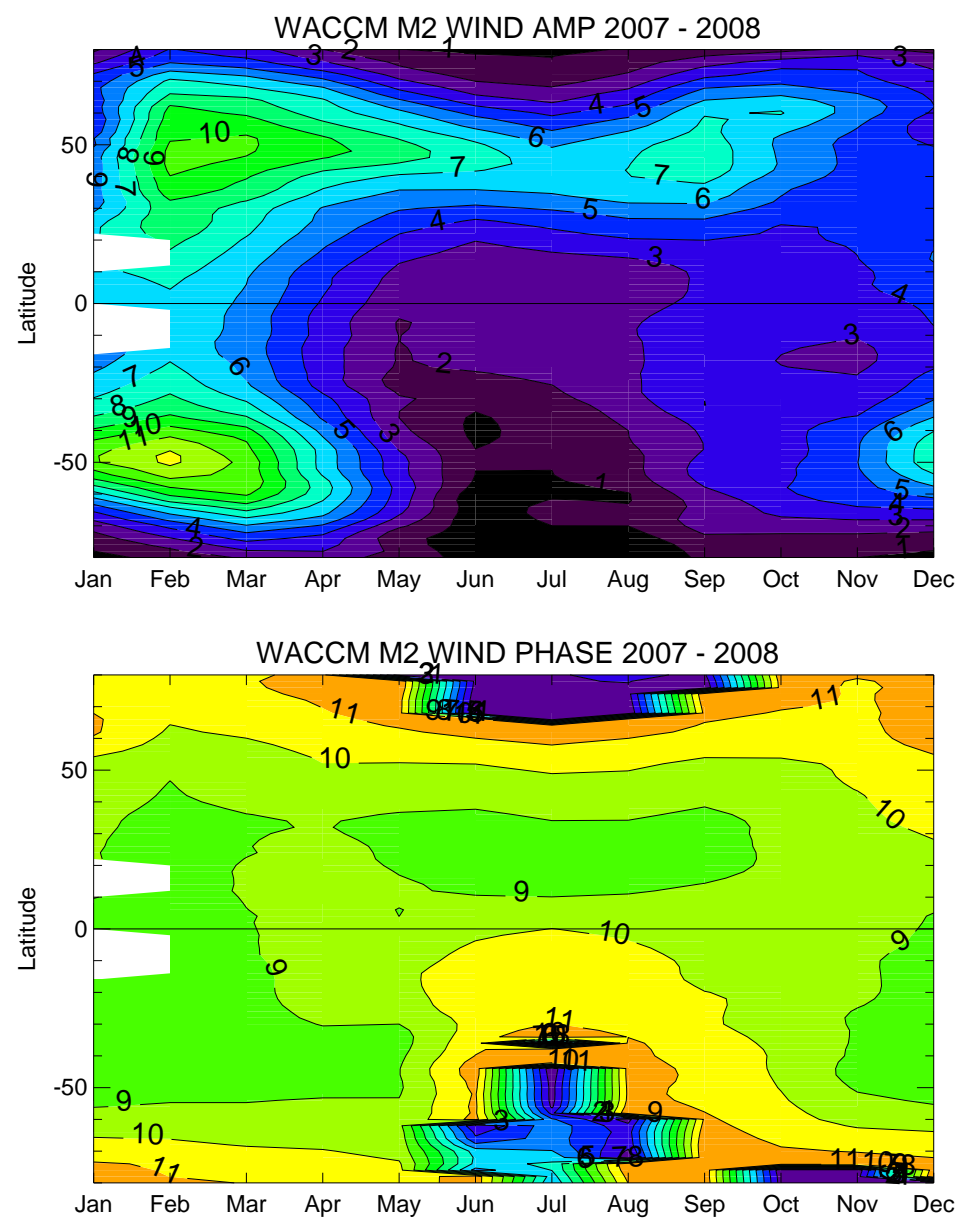

Figure 5: As in Figure 3, using WACCM-X values. 

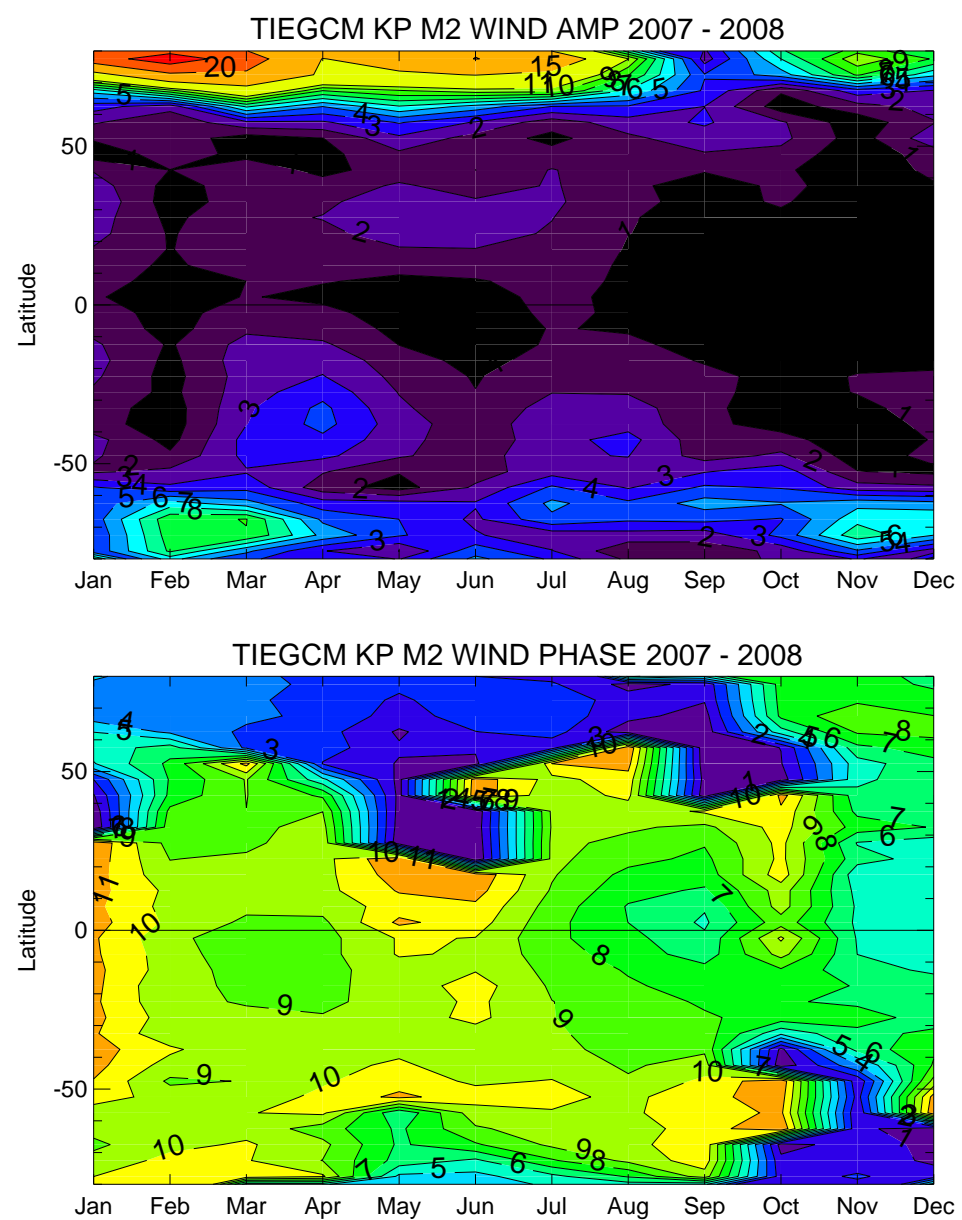

Figure 6: As in Figure 3, using values from the TIE-GCM. Contour values are 0-10, 15, 20, 25 , and 30 . 

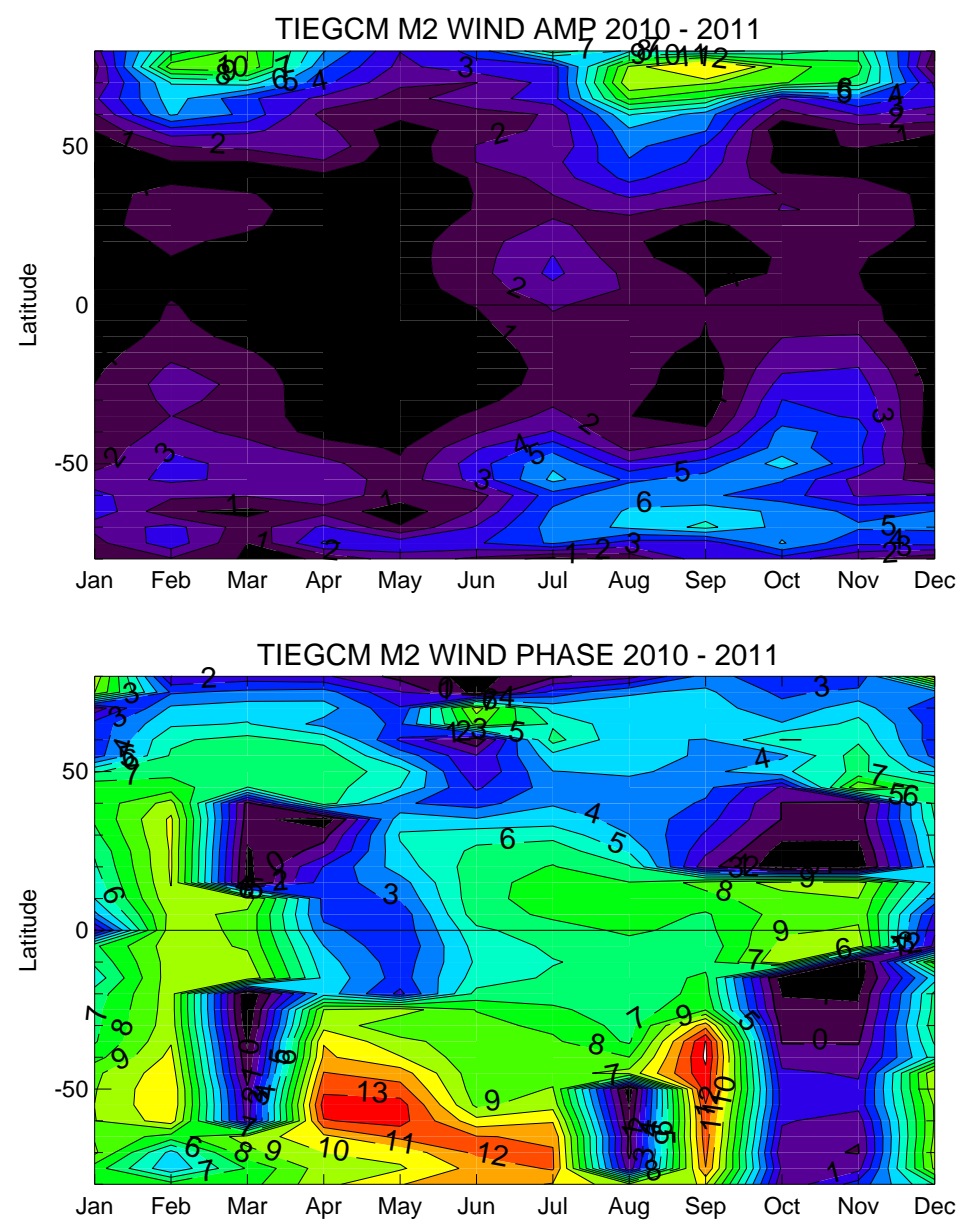

Figure 7: As in Figure 4, using values from the TIE-GCM during November 2009-August 2011. Contour values are $0-10,15,20,25$, and 30 . 

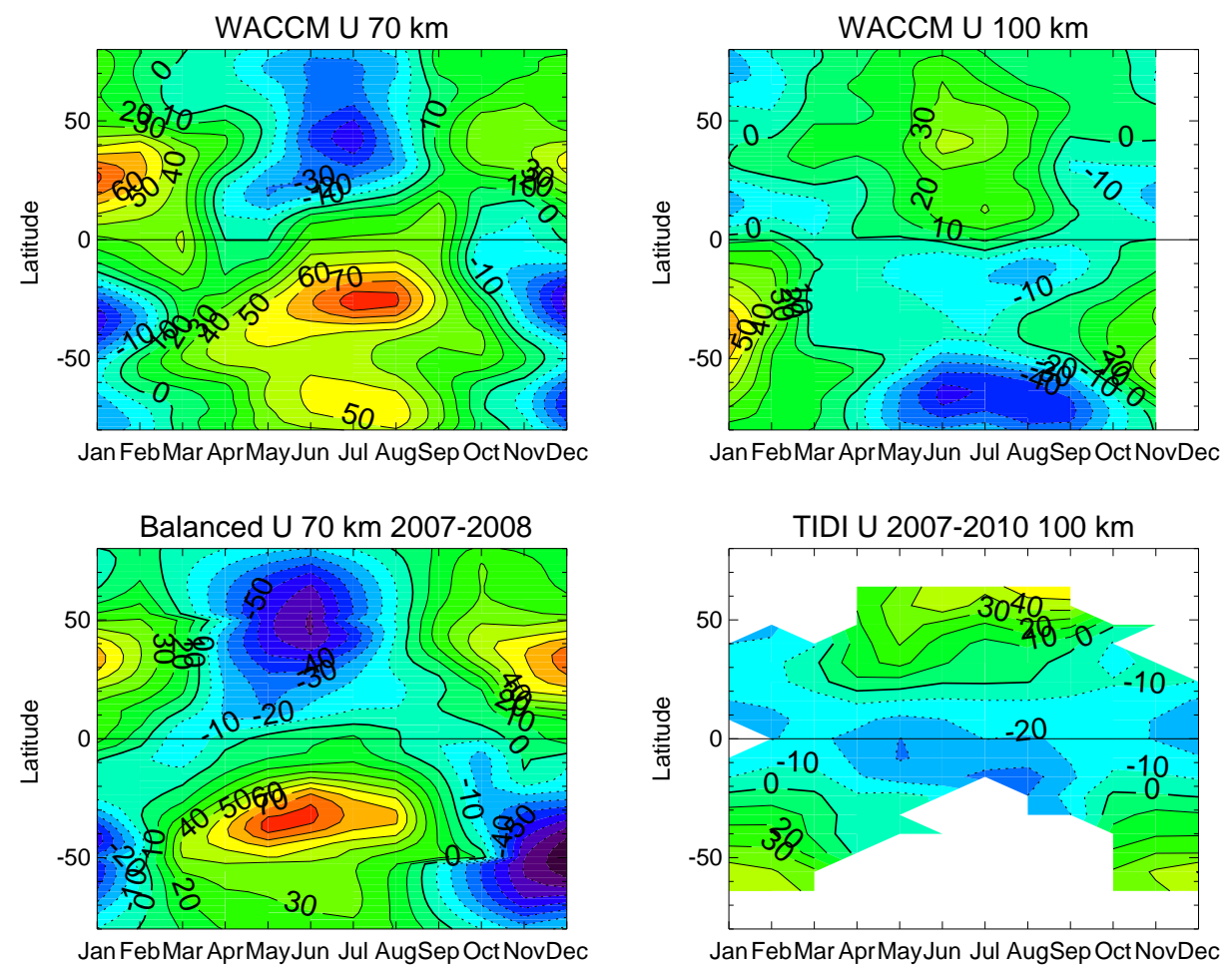

Figure 8: Left: Monthly mean $\bar{U}$ at $70 \mathrm{~km}$ in WACCM-X (top) and computed from SABER (bottom). Right: Monthly mean $\bar{U}$ at $100 \mathrm{~km}$ in WACCM-X (top) and TIDI (bottom). 

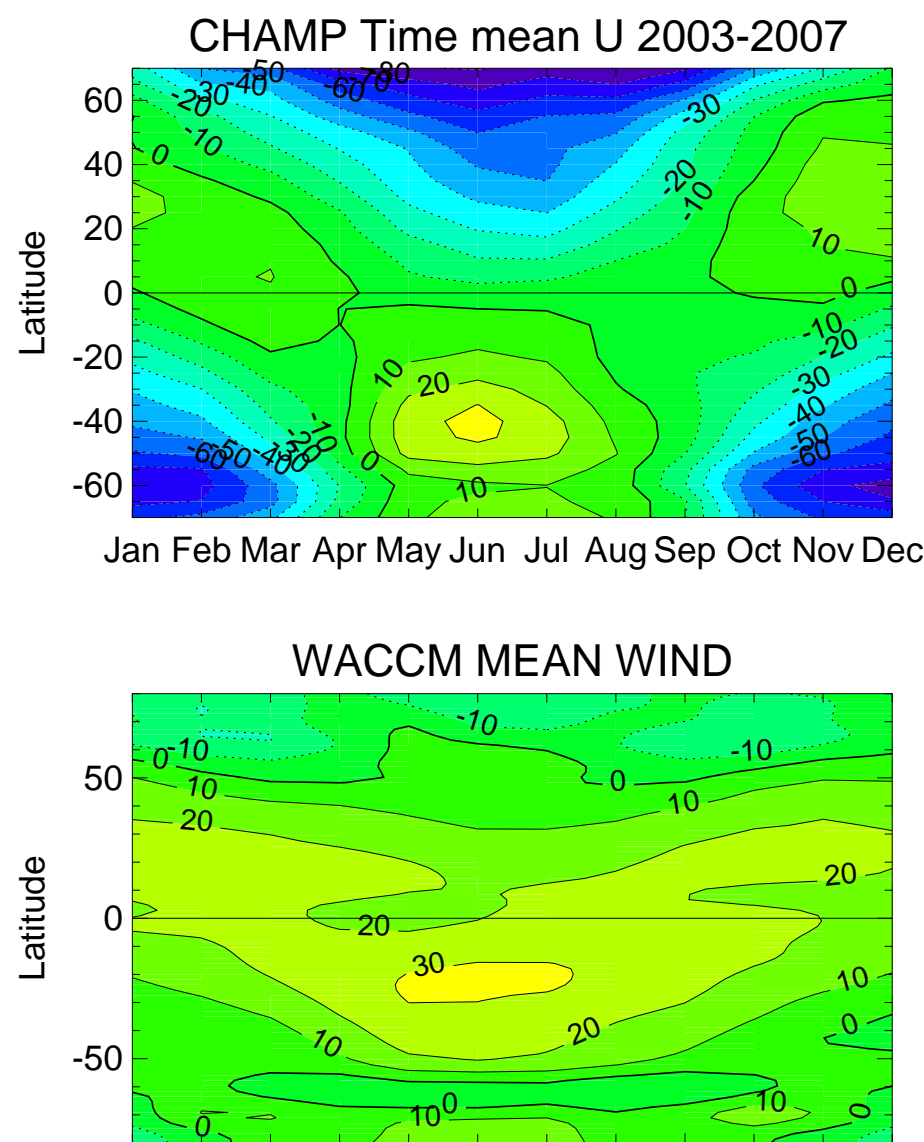

Jan Feb Mar Apr May Jun Jul Aug Sep Oct Nov Dec

Figure 9: Monthly mean $\bar{U}$ in CHAMP (top) and WACCM-X (bottom) at $350 \mathrm{~km}$. 